\title{
Research of Agricultural Big data
}

\author{
Hongyan $\mathrm{Li}^{1, \mathrm{a}}$, Ziyi Cheng ${ }^{2, \mathrm{~b}}$, Haitong Wang ${ }^{2, \mathrm{c}}$ \\ ${ }^{1}$ International Business School, Shaanxi Normal University, Xi' an, China \\ ${ }^{2}$ International Business School, Shaanxi Normal University, Xi' an, China
}

\begin{abstract}
With the development of economy and the popularization of Internet, the development of agricultural big data is the inevitable trend of agricultural development, which is gradually changing people' $\mathrm{s}$ lives. But there are many problems in the process of rural development. This paper will analyze the agricultural big data, from the meaning, significance, research status, problems and solutions of agricultural big data, in order to explore new ways for agricultural development, so as to promote the development of rural economy, improve the living standards of farmers and contribute to the construction of agricultural modernization.
\end{abstract}

\section{Introduction}

In recent years, with the popularity of computers, the Internet and the rise of Internet of Things, Cloud computing. Big data is gradually needed by all kinds of industry. Agriculture, as the most basic and traditional industry in China, is the guarantee of people's survival. With the arrival of the era of big data, the integration of agriculture and big data is an inevitable trend. The research of agricultural big data has an important practical significance.

\section{The meaning and significance of agricultural big data}

\subsection{The meaning of agricultural big data}

Agricultural big data belongs to a comprehensive technology. It contains concept, technology and specific measures. And it covers the entire range of agricultural activities, such as farming and sowing. There is a large amount of data in agricultural production process. For example, the illumination, temperature, humidity of the growth of crops and data on all aspects of the production process.

\subsection{The significance of developing agricultural big data}

As a large agricultural country, China has a large scale of agricultural production, there are many people engaged in agricultural production, processing and sale. In our country, different regional characteristics produces the different agricultural products, for many years, supply exceeds demand. As well as lack of information and other issues, a large number of agricultural products, such as fruits and vegetables, rotten in the fields of the countryside. Some mung beans, millet, buckwheat and other agricultural products have some problems. Their price is so cheap and they occasionally exist unsalable. At the same time, in firstand second-tier cities, because some agricultural products have limited resources, they are expensive and even difficult to purchase, which cannot meet people' s needs well. The main reason for the above problems is that Information is not smooth. China' s traditional agricultural technology level is not advanced, there are problems such as unsmooth information, few sales channels, and inadequate services. Agricultural big data is a specialized combination of agricultural professional data, resources and big data technology, theory and methods, and then applied to the agricultural field. With the characteristics of informatization, intelligence and precision, it can solve the problems encountered in traditional agriculture and provide new support for agricultural development. Agricultural big data can respond to the call of the country in the new era and promote the structural reform of agricultural supply side.

a2585941175@qq.com, bczy@snnu.edu.cn, c1219769143@qq.com 


\section{Research status of agricultural big data}

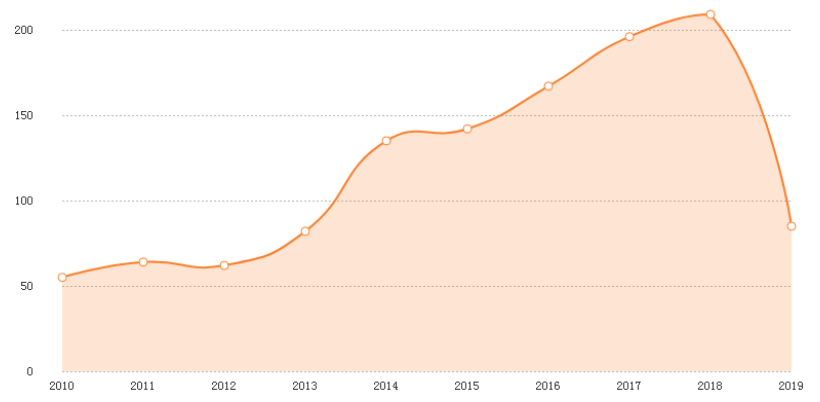

Figure 1 Published literature of agricultural big data in the latest ten years

a. From the Wanfang database

Through the data retrieval of Wanfang database, the published literature of agricultural big data in the latest ten years are retrieved, and the results are shown in Figure 1. From 2010 to 2019, the published literature of agricultural big data showed an overall upward trend, reaching the highest point in 2018, with 209 agricultural big data articles published.

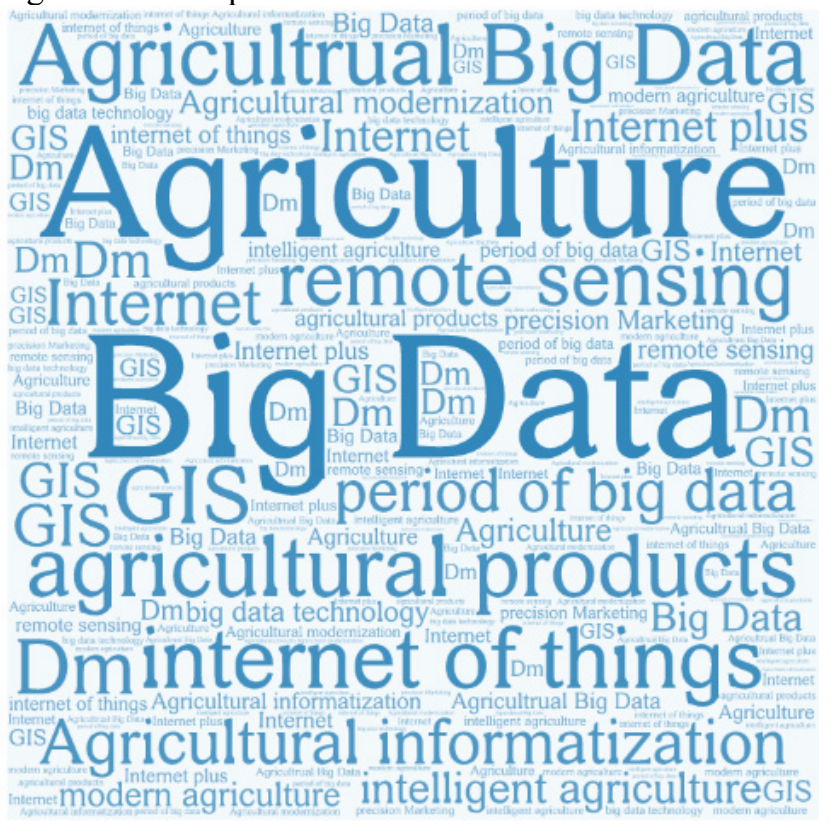

Figure 2 Key words of agricultural big data in the latest ten years b. From the Wanfang database

Through the data retrieval of Wanfang database, the key words of agricultural big data in the latest ten years are retrieved, and the results are shown in Figure 2. In the last decade, in addition to the two key words of big data and agriculture, the most frequent key words is agricultural big data. It can be seen that, in recent years, there are more and more researches on agricultural big data, and agricultural big data has become a research hotspot.

As can be seen from Figure 1 and Figure 2, there have been a lot of researches on agricultural big data in the last decade, and it is very necessary to study agricultural big data at present. However, the frequency of agricultural big data as a key word is only 34 times, and the annual amount of papers is relatively small. The research on agricultural big data is in the initial stage. So more researchers are needed to do more research and analysis on agricultural big data.

\section{Problems in developing agricultural big data}

Compared with cities, the actual situation in rural areas is relatively backward, whether in terms of infrastructure or living conditions. There are many problems in the process of agricultural and big data fusion.

\subsection{Less online sales of agricultural products and insufficient understanding of agricultural big data}

Farmers have traditional ideas, low education level, slow speed of accepting new things, few people use the network, people's understanding of the network is not objective enough, some farmers' understanding of the network is limited to chat entertainment, very few agricultural products are sold through the network. Farmers know less about big agricultural data, so it is difficult for farmers to fully understand and trust big agricultural data in a short time.

\subsection{Lack of agricultural big data talents in rural areas}

Nowadays, most of the people engaged in agricultural work in rural areas are after $60 \mathrm{~s}, 70 \mathrm{~s}$ and $80 \mathrm{~s}$. They generally do not pay enough attention to education in the era of reading. Therefore, the education level of rural people is generally not high. Developing agricultural big data is not enough to rely on local farmers. Moreover, the attraction of rural areas to talents is insufficient, and more technical talents who understand agricultural big data are needed.

\subsection{Rural equipment and facilities are backward}

Agricultural big data needs a series of work such as technical guidance, environmental monitoring and intelligent control. Due to the limited capacity of rural Internet and data processing, rural equipment and facilities can not meet the development conditions of agricultural big data. Agricultural big data needs a series of work such as technical guidance, environmental monitoring and intelligent control. Due to the limited capacity of rural Internet and data processing, rural equipment and facilities can not meet the development conditions of agricultural big data.

\section{Solutions to the development of agricultural big data}

In view of the actual situation in rural areas, this paper puts forward several solutions to agricultural big data to help agriculture and big data better integrate 
development and provide reform measures for agricultural modernization.

\subsection{Enhance network awareness and expand sales channels}

To guide e-commerce enterprises to support online sales of agricultural products. Developing e-commerce of agricultural products is an effective way to make people understand agricultural big data. In the process of traditional agricultural production and sales, the information between farmers and the outside world is asymmetric. Farmers blindly produce agricultural products "by experience" or "what was expensive last year and what was planted this year", which leads to oversupply and even unsalable agricultural products. Promote scientific planting and breeding in rural areas. First, the development of e-commerce of agricultural products can change the traditional idea that farmers can only buy backward agricultural products face to face, and online sales can provide a new way for agricultural products sales. Second, it is conducive to increasing employment opportunities, attracting more young talents to return to villages for employment or entrepreneurship, and contributing to slowing down the aging process of rural population. The third is to provide farmers with agricultural related information through big data, publish real-time prices of agricultural products, so that villagers can timely understand the price dynamics and avoid low-cost transactions. In order to enhance farmers' network awareness, improve farmers' understanding of big data, change traditional concepts, and constantly increase their trust in agricultural big data.

\subsection{Training and introduction of relevant talents}

To encourage and attract the urban big data, agricultural professionals and graduates to work in rural areas, and introduce high-quality professionals who are proficient in agricultural big data. At the same time, we should not only rely on the introduction of external talents to build rural areas, but also improve the overall quality of farmers through education, give lectures on agricultural big data in rural areas, answer questions on the spot, increase the interest of farmers. And select large farmers of planting and breeding in each village, and train relevant talents in rural areas through regular training courses, seminars, etc. Cultivate a group of new occupation farmers with data mining, analysis, integration and management knowledge, and create a " Internet plus big data" modern agricultural big data team.

\subsection{Strengthen the construction of rural equipment and facilities}

Apply to the government for allocating some financial funds to subsidize the development of agricultural big data, invite investment to purchase equipment and facilities and release policies to encourage the development of agricultural big data. For example, release big data specification for agricultural related services. Focus on cultivating and supporting a number of agricultural big data application and demonstration projects, and improve the level of rural informatization equipment and facilities.

\subsection{Attach importance to the development of agricultural big data}

At the national level, we should do a good job in supporting the development of big data, actively develop and utilize big data resources, and encourage scientific research on agricultural big data.

\section{Summary and Outlook}

In the field of agriculture, " big data" is a new word and high frequency word. The development of agricultural big data is conducive to the improvement of the level of agricultural informatization. Through strengthening the network awareness of farmers, broadening the sales channels, training and introducing relevant talents, strengthening the construction of rural equipment and facilities, and attaching importance to the development of agricultural big data, this series of countermeasures can solve the problem of unbalanced supply and demand of agricultural products and the lack of agricultural big data talents in rural areas, so as to open up new opportunities for agricultural products sales. Whether it is farmland construction, crop planting and harvesting or agricultural products processing and logistics, it is necessary to integrate and process data of different types and sources. Comprehensive and accurate data analysis can exploit new data and new conclusions, which is an important technology to realize agricultural modernization. In the future, big data will be widely used in various industries, especially in the field of agriculture. Through various efforts, agricultural big data must be trusted by people and become the key technology of agricultural development. Agricultural big data is bound to greatly improve agricultural efficiency and reduce agricultural production and sales costs.

\section{References}

In the process of writing this paper, I have read a lot of literature extensively, got a lot of inspiration and inspired a lot of good thinking. Here, I would like to express my sincere gratitude and respect to the researchers who are engaged in relevant research.

1. Li Jianbo, Li Xiaohua and Peng Yibo, "Application of Big Data in Agricultural Internet of Things," vol.36. China: Hunan, 2019, pp.1521-1529, 2019.

2. Zhou XC, Chen YM and Zhu XH. " A kind of agricultural internet of things big data platform architecture," Agric Sci 2019. China: Anhui, vol .47, pp. 241-245, 2019.

3. $\mathrm{Na} \mathrm{Li} \mathrm{and} \mathrm{Nitaigour} \mathrm{Premchand} \mathrm{Mahalik.} \mathrm{"} \mathrm{A} \mathrm{big}$ data and cloud computing specification, standards and architecture: agricultural and food informatics," International Journal of Information and 
Communication Technology, vol.14, pp.159-174, 2019.

4. Zhao LN. " Research on the application and development of agricultural internet of things technology, " Inf Rec Mater 2019. vol .20, pp. 100-101.

5. Zhang Chunling and Liu Zunfeng. " Application of big data technology in agricultural Internet of Things, " Impact Factor, vol. 15, Oct. 2019.

6. Ryan, Mark. " Agricultural Big Data Analytics and the Ethics of Power," Journal of Agricultural and Environmental Ethics. vol. 33. pp. 49-69, Nov. 2019.

7. Keith H. Coble, Ashok K. Mishra, Shannon Ferrell, and Terry Griffin. " Big Data in Agriculture: A Challenge for the Future, " Applied Economic Perspectives and Policy, vol. 40, pp. 79-96, 2018.

8. K. Kareemulla and S. Ravichandran. AGRICULTURAL DATA ANALYTICS - SMALL TO BIG DATA, " International Journal of Agricultural and Statistical Sciences, vol.14, pp. 211-214, 2018.

9. Lu L and Kang PZ. " Application of agricultural internet of things technology in grape planting, " Agric Sci Bull 2018. China: Anhui, vol. 23, pp. 122-124, 2018.

10. Rao, N. H. " Big Data and Climate Smart Agriculture - Status and Implications for Agricultural Research and Innovation in India, " Proc Indian Natn Sci Acad . vol.84, pp. 625-640, Sep. 2018.

11. Biffis, E. and Chavez, E. " Satellite data and machine learning for weather risk management and food security," Risk Analysis, vol.37, pp. 15081521, 2017.

12. Carolan, M. " Publicising food: Big data, precision agriculture, and co-experimental techniques of addition, " Sociologia Ruralis, vol. 57, pp. 135-154, 2017.

13. Kamilaris, Andreas, Kartakoullis, Andreas, Prenafeta-Boldu and Francesc X. " A review on the practice of big data analysis in agriculture, "Computers and Electronics in Agriculture, vol.142, pp. 23-37, Dec. 2017.

14. Geetha, G and Priya, N. " Dynamic Programming Based Resource Optimization in Agricultural Big Data for Crop Yield Maximization, " Journal of computational and theoretical nanoscience, vol.14, pp. 4464-4470, 2017.

15. T. Papadopoulos, A. Gunasekaran, R. Dubey, N. Altay, S. J. Childe, S. Fosso-Wamba, " The role of big data in explaining disaster resilience in supply chains for sustainability," J. Cleaner Prod., vol. 142, pp. 1108-1118, 2017.

16. Li Heqiang, Wang Chunlong and Wang Yingying. "The idea of constructing big data processing system of Agricultural Internet of things from the Perspective of opportunity Cooperation," Electronic
Technology and Software Engineering, vol.16, pp. 153, 2017.

17. Zhao Changhua, Michun Bridge. " Research on Agricultural Information Fusion method based on ontology in big data era, " Journal of Huaihua University, vol.3605, pp. 41-45, 2017.

18. Wen Fujiang and Song Changqing, "Agricultural big data Application, Research and Prospect, Agricultural Network Information, vol.5, pp. 31- 36, 2017.

19. Carbonell, I. M.. "The ethics of big data in big agriculture," Internet Policy Review, vol.5, pp. 1-13, 2016.

20. Coble, K., T.W. Griffin, M. Ahearn, S. Ferrell., J. McFadden, S. Sonka, and J. Fulton. Advancing U.S. " Agricultural Competitiveness with Big Data and Agricultural Economic Market Information, Analysis, and Research," Washington DC: Council on Food, Agricultural, and Resource Economics, 2016.

21. D. Mishra, A. Gunasekaran, T. Papadopoulos, S. J. Childe, "Big data and supply chain management: A review and bibliometric analysis", Ann. Oper. Res., pp. 1-24, Jun. 2016.

22. Sykuta, M.E. " Big data in agriculture: Property rights, privacy and competition in ag data services, " The International Food and Agribusiness Management Review, pp. 57-74, 2016.

23. Wang Wensheng and Guo LeiFeng. " Tentative ideas on the Construction of Agricultural big data Center in China, "Big data,vol.1, pp. 28-34, 2016.

24. Wu Li. " Big data drives the New path of Agricultural Development, " Today Pig Industry, vol.3, pp. 84, 2016.

25. Liu Hanyuan. "Set up an agricultural big data platform to speed up the development of intelligent agriculture in China," China Cooperative Economy, vol.3, pp. 121-122, 2016.

26. Guo Lei Feng. "Research on big data 's key Technologies in the Field of Agriculture, " Chinese Academy of Agricultural Sciences, 2016.

27. Wang Xijun and Huang Jinhong. "Lead new development with new ideas, "Shandong people' s Publishing House, pp. 211, 2016.

28. Li Lingping, Mao Kebiao, Fu Xiuli, Ma Ying, Wang Fang and Liu Bo. " Research and Analysis on the Application of Agricultural big data at Home and abroad, " High Technology Newsletter, vol. 26, pp. 414-422, 2016.

29. Bendre M R, Thool RC and Thool V R. "Big data in prec is ion agr iculture: Weather forecasting for future farming, " Internat ional Conferenceon Next Generation Computing Technologie, IEEE, pp. 744750, 2016.

30. Xie Runmei. "Acquisition and utilization of agricultural big data, " Anhui Agricultural Science, vol.43, pp. 383, 2015. 
31. Guangfeng, Yao Chengkuan and Wang Weijin. " A study on the Application of big data in the Field of Agriculture, " Journal of Luoyang normal University, vol. 340, pp. 75-77, 2015.

32. Yang Jin. "Agricultural Standardization under the background of big data, " Papers of the 12th China Standardization Forum, 2015.

33. Yang Ying and Cui Yunpeng. "Key Technology and Future Development of Intelligent Agriculture in China, " Information Technology and Standardization, vol. 6, pp. 35- 37, 2015.

34. Li Xuelong and Gong Haigang. "Big data system Summary," Information Science, vol.1, pp. 1- 44. 2015.

35. Zhang Jian, "Research and Application of Agricultural Geographic data Visualization Technology based on WebGIS, " Zhejiang University, 2015.

36. Meng Xiangbao, Xie Qiubo and Liu Haifeng. "Agricultural big data Application Architecture and platform Construction, " Guangdong Agricultural Science, vol. 14, pp. 173 -177, 2014.

37. Xu Shiwei. "Agricultural big data and Agricultural products Monitoring and early warning, " China Agricultural Science and Technology Guide, vol.16, pp. 14-20, 2014.

38. Fan, J., F. Han, and H. Liu. "Challenges of Big Data Analysis, " National Science Review, vol. 1, pp. 293-314, 2014.

39. M. Chen, S. Mao, Y. Liu, "Big data: A survey", Mobile Netw. Appl., vol. 19, no. 2, pp. 171-209, Apr. 2014.

40. Zhang Haoran, Li Zhongliang, Zou Tengfei, Wei Xuyang and Yang Guocai. "A Summary of
Agricultural big data, " Computer Science, pp. 387 392, 2014.

41. Li Xiufeng, Chen Shouhe and Guo LeiFeng. "Technological Innovation of Agricultural Information Service in big data era, " China Agricultural Science and Technology Guide, vol.4, pp. 10- 15, 2014.

42. Ludena RD A and Ahrary A. "A Big Data Approach for a New ICT Agriculture Application Development, "International Conference on Cyberenabled Distribut ed Computing and Knowled ge Discovery, IEEE Computer Society, pp. 140-143, 2013.

43. Chen Tianchao, "Overview of the basic structure of Internet of things Technology, " Forest area Teaching, vol.3, pp. 10-15. 2013.

44. Sun Zhongfu, du Kemin., "Big data's Research and Application Prospect in Intelligent Agriculture, " Introduction to China's Agricultural Science and Technology, vol.15, pp. 63- 71, 2013.

45. M. A. Waller, S. E. Fawcett, "Data science predictive analytics and big data: A revolution that will transform supply chain design and management", J. Bus. Logistics, vol. 34, pp. 77-84, 2013.

46. Wu Wenjing. "Research on the Design of Internet of things Scheme of Gansu Tobacco Company, " Lanzhou University, 2011.

47. Liu Haiqi. "A brief introduction to the Application of Agricultural remote Sensing Technology in the United States, "sense of Land and Resources, vol.3, pp. 58-62, 1997. 